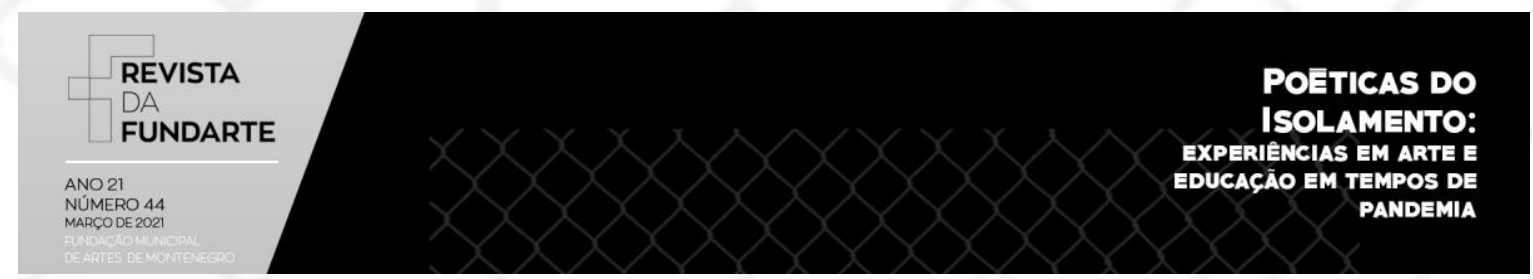

\title{
O ENXERIMENTO: A PRÁTICA DO GRUPO MAGILUTH E O ESPECTADOR EMANCIPADO DE JACQUES RANCIÈRE
}

Railson Gomes Almeida'

\begin{abstract}
Resumo: O Grupo Magiluth estreia em 2020 o experimento sensorial em confinamento Todas as histórias possíveis, uma experiência cênica de observação individual, no qual cada seção é conduzida por um artista do grupo que entra em contato com o público à distância por recursos como telefone e a internet. O espectador é convidado a adentrar na dramaturgia e procurar ela ao lado do artista em tempo real, esse sujeito deixa de ser apenas um observador passivo da obra e emancipase, sendo parte crucial da proposta ao lado do próprio artista, dialogando assim o conceito de Espectador Emancipado de Jacques Rancière que discute sobre os limites inexistentes entre espectador e obra de arte na contemporaneidade, sendo nessa reconfigurado para o termo enxerido (utilizado no nordeste brasileiro) para designar a ousadia ou o enxerimento do sujeito em fazer parte da cena.
\end{abstract}

Palavras-chaves: Grupo Magiluth; Espectador emancipado; Espectador enxerido

\section{THE BOLDNESS: THE PRACTICE OF THE MAGILUTH GROUP AND THE EMANCIPATED SPECTATOR OF JACQUES RANCIĖRE}

\begin{abstract}
The Magiluth Group debuts in 2020 the sensory experiment in confinement Todas as histórias possíveis, a scenic experience of individual observation, in which each section is conducted by an artist of the group who gets in touch with the public at a distance through resources such as telephone and the internet. The spectator is invited to enter the dramaturgy and look for it beside the artist in real time, this subject is no longer just a passive observer of the work and emancipated being a crucial part of the proposal beside the artist himself, Thus dialoguing the concept of Emancipated Spectator by Jacques Rancière who discusses the non-existent limits between spectator and work of art in contemporaneity, being in this reconfigured for the term enxerido (used in the Brazilian northeast) to designate the audacity or the sight of the subject in being part of the scene.
\end{abstract}

Keywords: Magiluth Group; Emancipated spectator; Boldness spectator;

\section{INTRODUÇÃO}

O ano de 2020 foi marcado como sendo o ano da maior crise de saúde global das últimas décadas, devido ao anúncio da pandemia causada pelo vírus SARSCoV-2 (novo coronavírus), causador da doença COVID-19, o que obrigou governos

\footnotetext{
${ }_{1}$ Professor Substituto do IF sertão - Campus Floresta; Doutorando em Teatro pela UDESC; Mestre em Artes Cênicas pela UFRN; Bacharel e licenciando em Teatro pela UFPB.
}

ALMEIDA, Railson Gomes. O enxerimento: a prática do Grupo Magiluth e o espectador emancipado de Jacques Rancière. Revista da FUNDARTE. Montenegro, p.01-11, ano 21, oㅡ 44, janeiro/março de 2021.

Disponível em: http://.seer.fundarte.rs.gov.br/index.php/revistadafundarte/index> 30 de março de 2021. 


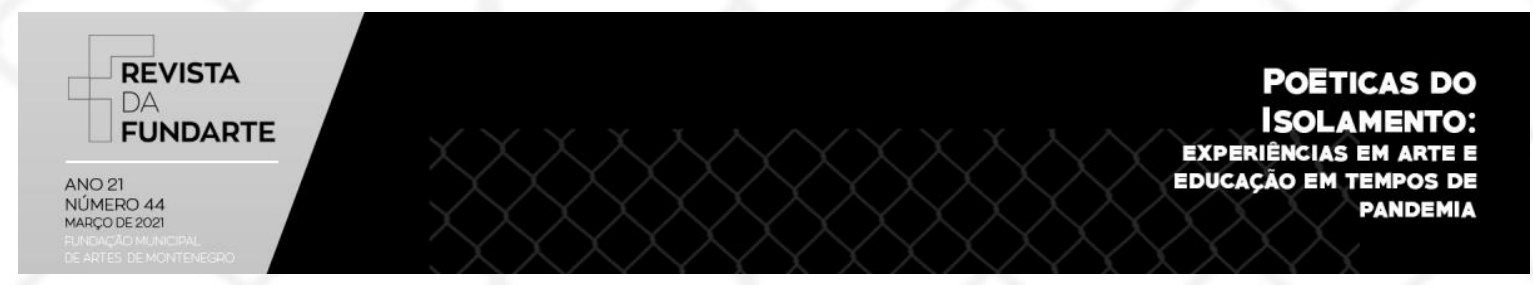

de todo o mundo a decretarem medidas preventivas de isolamento social, distanciamento social e uma longa quarentena, obrigando assim o fechamento de estabelecimentos públicos e privados, a exceção de equipamentos e serviços essenciais, por tempo indeterminado.

No Brasil não foi diferente, por mais que as medidas fossem criticadas por parte da população, tivemos um processo de quarentena, sendo assim foi recomendado que a população ficasse em casa e não se expusesse. Todos os setores comerciais foram direta ou indiretamente impactados, sofrendo reduções, ou até mesmo parando seus serviços por algum tempo. Um dos mais atingidos certamente, foi o das artes da cena, por se tratar, justamente, de um ofício que lida diretamente com apresentações ao vivo e em tempo real, mantendo assim um contato direto entre artista e público.

Logo, esses artistas tiveram que pausar seus processos criativos, cancelar por tempo indeterminado suas apresentações, e assim aguardar até o encerramento da quarentena, quando fosse seguro voltar à normalidade, o que não aconteceu, ainda, enquanto escrevo no início de janeiro de 2021.

Porém todo esse processo dificultoso de 2020, fez com que alguns artistas se reinventassem para continuarem ativos no fazer artístico, e ainda sobreviver de algum modo. Diferentes propostas individuais e coletivas surgiram, algumas buscando o registro gravado de apresentações ao vivo, apresentações gravadas e reproduzidas em sites online. Mas, outros buscaram maneiras de reinvenção da cena artística em tempo real, utilizando aplicativos e plataformas da internet como os coletivos paulistas: Os satyros e a Cia Mugunzá de Teatro. Ambas apresentavam em tempo real para um público que acompanhava, ao vivo, todo o espetáculo por meio de um aplicativo.

Outra dessas propostas inovadoras foi realizada pelo Grupo Magiluth, coletivo de teatro da cidade de Recife, em Pernambuco, no Nordeste brasileiro, com o Todas

ALMEIDA, Railson Gomes. O enxerimento: a prática do Grupo Magiluth e o espectador emancipado de Jacques Rancière. Revista da FUNDARTE. Montenegro, p.01-11, ano 21, oㅡ 44, janeiro/março de 2021.

Disponível em: http://.seer.fundarte.rs.gov.br/index.php/revistadafundarte/index> 30 de março de 2021. 


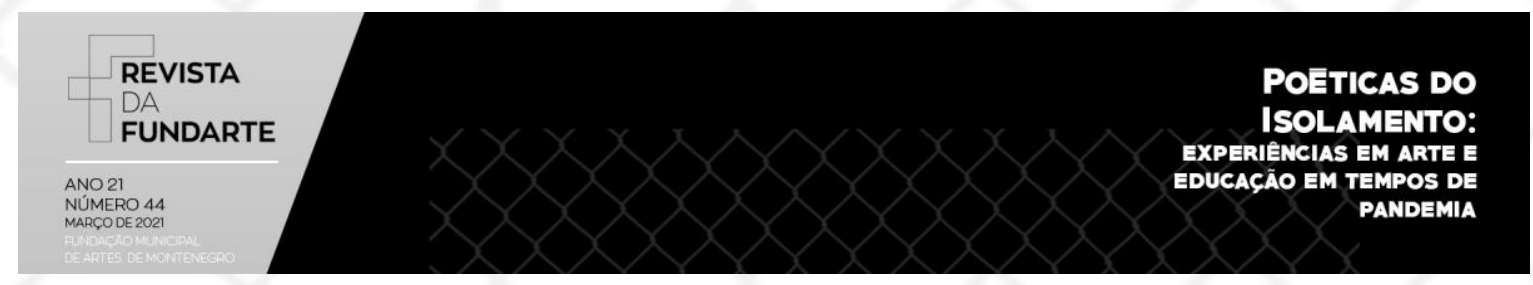

as histórias possíveis, um "experimento sensorial em confinamento", como assim foi classificado, e nomeada a proposta pelo próprio grupo.

Todas as histórias possíveis, consiste no contato direto e individual com o espectador, que ao se inscrever para o experimento, coloca alguns dados pessoais, como o número do telefone e o contato em redes sociais. Enquanto público, nós recebemos com antecedência algumas instruções, bem como a hora em que será realizado o encontro artístico. No momento marcado, recebe-se uma ligação de um dos atores, que conduzirá o espetáculo informando instruções, enviando materiais para serem acessados, etc. Tornando possível a interação da obra de arte com o público, não importando o distanciamento físico entre as partes.

Tal procedimento, por mais inovador que seja, foi discutido pelo teórico francês Jacques Rancière, no ensaio $O$ espectador emancipado, publicado em 2008 em livro de nome homônimo, o autor fala acerca da emancipação do espectador dentro de obras de arte na contemporaneidade, atribuindo esse sujeito, não como observador passivo de uma obra, mas no questionamento da "oposição entre olhar e agir", tornando o público, em outras palavras, como parte crucial da obra em si.

Sendo assim, o objetivo dessa escrita é refletir o trabalho Todas as histórias possíveis do Grupo Magiluth, observando a discussão acerca do espectador emancipado, proposta pelo Ranciére, a qual estou intitulando aqui de "enxerimento". Para tanto, escrevo sobre minha experiência, enquanto espectador enxerido do trabalho. Depois falo sobre a leitura do autor francês, para então finalizar com uma breve reflexão acerca de tudo isso.

\section{A EXPERIÊNCIA DE SER UM ESPECTADOR ENXERIDO}

Era uma noite qualquer, talvez uma quinta-feira, daquelas completamente normais, em que os sujeitos estão navegando na internet e preparando-se mentalmente para dormir. Foi por volta das 23:30 que recebo uma ligação. Era

ALMEIDA, Railson Gomes. O enxerimento: a prática do Grupo Magiluth e o espectador emancipado de Jacques Rancière. Revista da FUNDARTE. Montenegro, p.01-11, ano 21, no 44, janeiro/março de 2021.

Disponível em: http://.seer.fundarte.rs.gov.br/index.php/revistadafundarte/index> 30 de março de 2021. 


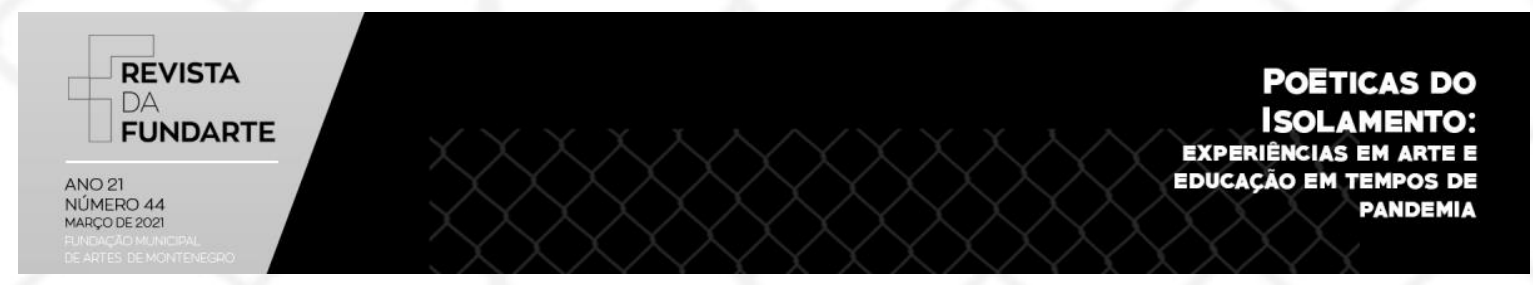

Giordano Castro, ator do Grupo Magiluth que me ligava, perguntou alguma coisa a respeito do meu dia, e aproveitei para elogiar o trabalho do grupo que acompanho faz alguns anos. Alguns minutos depois dessa conversa, ele fala que a peça "Todas as histórias possíveis" começou.

Não lembro se Giordano leu algum prólogo, ou se todo esse texto introdutório foi dissolvido em meio ao nosso diálogo, que parecia a todo o momento banal, e cotidiano. No final da ligação, ele pede que fique atento ao whatssap, pois ali me mandaria instruções. Alguns minutos depois textos me eram mandados, era a personagem que conversava comigo. Creio que se apresentou a mim, e em seguida falou do seu namorado e de um conflito com a chave de seu apartamento. As minúcias da história se perderam da memória.

Após alguns textos, recebi links de um site que simulava uma rádio, tocava repetidamente, uma música seguida de um texto dito pelo radialista. Depois outras mensagens no WhatsApp e o enredo evoluía na minha frente, no tempo real de uma conversa via mensagem de texto. Creio que recebi outra ligação, era o Giordano perguntando se estava acompanhando bem o processo, afirmativamente disse que sim, e acredito que elogiei antecipadamente a proposta que ainda não tinha findado.

Outros diálogos ditos pelo WhatsApp, alguns inclusive em áudios, depois acho que recebi um vídeo curto e no final de tudo, um link para um vídeo mais longo no Youtube. Era o fechamento da história, a qual foge da memória agora, mas que naquele momento se encaixava, lembro inclusive que me emocionei. Para fechar a peça, outra ligação do Giodano, pediu algum feedback, agradeceu a minha disponibilidade, falou da ficha técnica e do patrocínio, que naquela ocasião era o Sesc Avenida Paulista. Ele pede que abra meu Instagram, e finaliza a conversa saudando-me com um "Boa noite, obrigado pela presença". E só me resta agradecer pela brilhante experiência.

No Instagram, recebi uma mensagem do Grupo Magiluth. Eles me mandam um link de uma playlist colaborativa do Spotify, no qual devia colocar uma música 


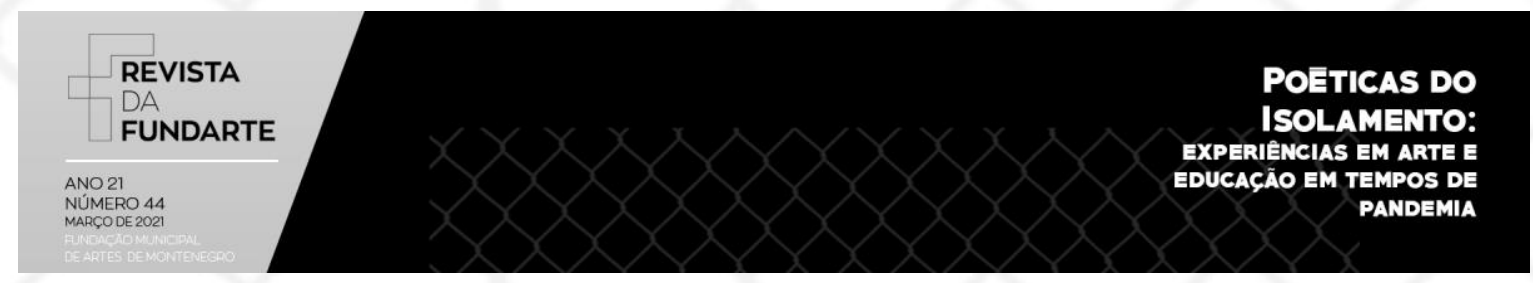

que gostava muito. Eles ainda perguntaram da minha experiência e pediram que eu fizesse um agradecimento público/convite para outras pessoas.

Quando acabou, tentei revisar a peça, acompanhando novamente todos os textos recebidos no WhatsApp, bem como abri novamente os links. Mas tudo foi apagado, e tudo que me restou foram as poucas lembranças, e a beleza daquele experimento que me marcou. Naquela noite dormi feliz pelo teatro que tive a oportunidade de vivenciar, foi efêmero tudo aquilo, afinal é teatro e a efemeridade faz parte da nossa lida.

\section{NOTAS DO ESPECTADOR EMANCIPADO DE JACQUES RANCIĖRE}

A emancipação [é] o embaralhamento da fronteira entre os que agem e os que olham, entre indivíduos e membros de um corpo coletivo. (RANCIĖRE, 2012, p. 23).

A obra $O$ espectador Emancipado do filósofo francês Jacques Rancière é composta de cinco ensaios onde o autor busca suscitar o papel do espectador numa abordagem filosófica e social, procurando entender como essa figura está inserida na contemporaneidade, nos diversos campos da arte e politica.

Para nossa pesquisa, iremos nos ater apenas ao primeiro ensaio, o qual se intitula a obra, percebendo que sua discussão é mais relevante para esse estudo do que os demais ensaios presentes no livro. Sendo assim, seguimos nosso comentário ao recorte do ensaio $O$ espectador emancipado.

O autor introduz afirmando que a escrita desse ensaio partiu de uma provocação feita por um grupo de artistas a partir da leitura da obra $O$ mestre ignorante$^{2}$. A princípio tal provocação causou estranhamento, mas num segundo

2 "Tal livro descreve a relação pedagógica do embrutecimento, a qual considera que existe uma distância interminável entre a posição do mestre e a do ignorante. Sob tal ótica, o primeiro apenas pode aproximar o seu saber da ignorância do segundo e recriar incessantemente tal distância, pois

ALMEIDA, Railson Gomes. O enxerimento: a prática do Grupo Magiluth e o espectador emancipado de Jacques Rancière. Revista da FUNDARTE. Montenegro, p.01-11, ano 21, oㅡ 44, janeiro/março de 2021.

Disponível em: http://.seer.fundarte.rs.gov.br/index.php/revistadafundarte/index> 30 de março de 2021. 


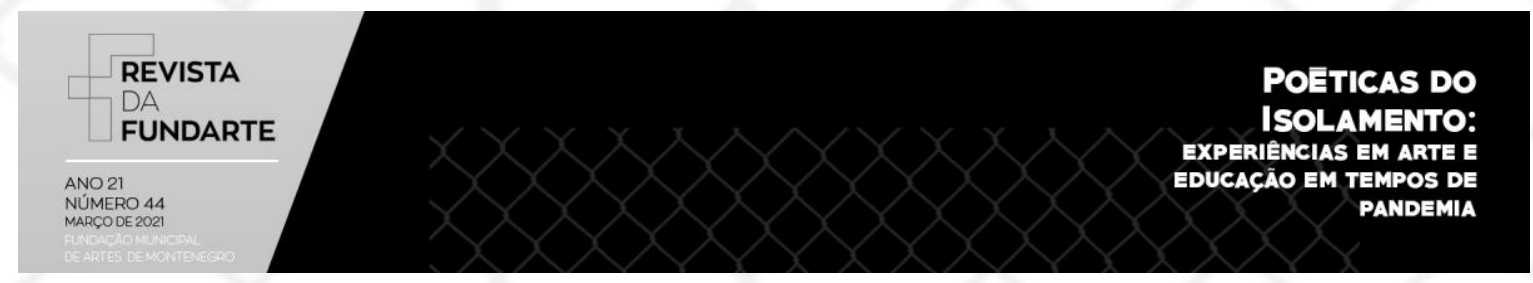

momento, mostrou um olhar potente para essa relação entre o espectador e o aluno "ignorante".

A escrita é iniciada apresentando a importância e relevância da figura do espectador, a priori, entre as relações e discussões entre arte e política. O francês então apresenta o paradoxo do espectador que se formula, em outras palavras, a partir de uma relação contrária onde: não existe teatro ${ }^{3}$ sem espectador, sendo assim, o espectador torna-se elemento essencial do fazer teatral; mas é maldoso ser um espectador ${ }^{4}$, pois trás uma relação de passividade e de imobilidade, onde esse ouvinte não consegue habitar outro espaço que não seja seu assento, perdendo o potencial de interlocução entre os envolvidos, ou seja, "ser espectador é estar separado, ao mesmo tempo, da capacidade de conhecer e do poder de agir" (RANCIÈRE, 2012, p. 8).

Baseado neste diagnóstico da negatividade de ser espectador é possível concluir que "o teatro é uma coisa absolutamente ruim, uma cena de ilusão e passividade que é preciso eliminar em proveito daquilo que ela impede: o conhecimento e a ação, a ação de conhecer e a ação conduzida pelo saber" (RANCIÈRE, 2012, p. 8). Tal conclusão se relaciona diretamente com a formulação de Platão: "o teatro é o lugar onde ignorantes são convidados a ver sofredores. 0

sua posição exige que esteja sempre um passo a frente. Já a emancipação intelectual, também descrita na obra, prega a igualdade das inteligências. Segundo ela, o ignorante não precisa transpor um abismo entre a sua ignorância e o saber do mestre, mas apenas cruzar o caminho daquilo que já sabe até aquilo que ignora, apreendendo signo após signo a relação entre o que ignora e o que sabe. O mestre ignorante é aquele que ignora a noção de inteligências desiguais. Para ele não existem fronteiras e hierarquias fixas nas posições do mestre e do ignorante." (HOULLOU \& JULIANO, 2013, p. 419)

${ }^{3}$ É empregada a expressão espetáculo teatral ou teatro, no entanto o autor busca incluir em sua discussão "todas as formas de espetáculo - ação dramática, dança, performance, mímica ou outras que ponham corpos em ação diante de um público reunido." (RANCIERE, 2012, p. 8)

4 "É um mal ser espectador, por duas razões. Primeiramente, olhar é o contrário de conhecer. O espectador mantém-se diante de uma aparência ignorando o processo de produção dessa aparência ou realidade por ela encoberta. Em segundo lugar, é o contrário de agir. O espectador fica imóvel em seu lugar, passivo." (RANCIĖRE, 2012, p.8).

ALMEIDA, Railson Gomes. O enxerimento: a prática do Grupo Magiluth e o espectador emancipado de Jacques Rancière. Revista da FUNDARTE. Montenegro, p.01-11, ano 21, oㅡ 44, janeiro/março de 2021.

Disponível em: http://.seer.fundarte.rs.gov.br/index.php/revistadafundarte/index> 30 de março de 2021. 


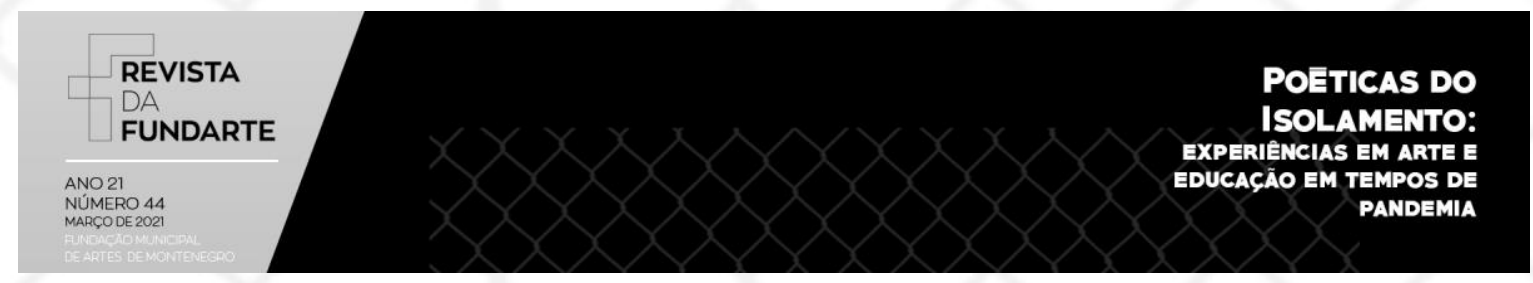

que a cena teatral lhes oferece é o espetáculo de um páthos ${ }^{5}$, a manifestação de uma doença, a doença do desejo do sofrimento." (RANCIÈRE, 2012, p.9).

Apresentado esse paradoxo do espectador, é possível perceber que o autor propõe uma crítica indireta as obras de arte herméticas, ou seja, obras fechadas, ensimesmadas, onde espectador, por mais necessário que seja, assume papel secundário e irrelevante dentro da obra em si.

É quando Rancière faz um apelo a um teatro sem espectadores, que não seria um teatro com assentos vazios, mas um teatro onde o drama assume seu real significado a todos os envolvidos, a ler: Ação. Um teatro "onde uma ação é levada à sua consecução por corpos em movimento diante de corpos vivos a mobilizar. [...] [onde os ouvintes] aprendam em vez de ser seduzidos por imagens, na qual eles se tornem participantes ativos em vez de serem voyeurs passivos." (RANCIÈRE, 2012, p. 9).

São citados então duas metodologias/estéticas teatrais, onde é possível observar uma postura diferenciada do espectador, que parte de proposituras dos artistas, ou seja, a obra intencionalmente busca suscitar relação com o ouvinte, sendo tal relacionamento espectador-obra necessária para a proposta.

Primeiro é citado o teatro do teatrólogo alemão Bertolt Brecht ${ }^{6}$, o qual propõe uma "mediação teatral [que] torna [os espectadores] conscientes da situação social que lhe dá ensejo e desejosos de agir para transformá-la" (RANCIÈRE, 2012, p. 13). Ele propõe isso por meio do seu teatro épico que busca o distanciamento do artista

\footnotetext{
5 SIGNIFICADO DE PATHÓS: Palavra grega que significa paixão, excesso, catástrofe, passagem, passividade, sofrimento, assujeitamento, sentimento e doença.

(FONTE: https://pt.wikipedia.org/wiki/Pathos)

6 Segundo a teoria brechtiana "é preciso arrancar o espectador ao embrutecimento do parvo fascinado pela aparência e conquistado pela empatia que o faz identificar-se com as personagens da cena. A este será mostrado, portanto, um espetáculo estranho, inabitual, um enigma cujo sentido ele precise buscar. Assim, será obrigado a trocar de posição de espectador passivo pela de inquiridor, ou experimentador cientifico que observa os fenômenos e procura suas causas" (RANCIÈRE, 2012, p. 10).
}

ALMEIDA, Railson Gomes. O enxerimento: a prática do Grupo Magiluth e o espectador emancipado de Jacques Rancière. Revista da FUNDARTE. Montenegro, p.01-11, ano 21, no 44, janeiro/março de 2021.

Disponível em: http://.seer.fundarte.rs.gov.br/index.php/revistadafundarte/index> 30 de março de 2021. 


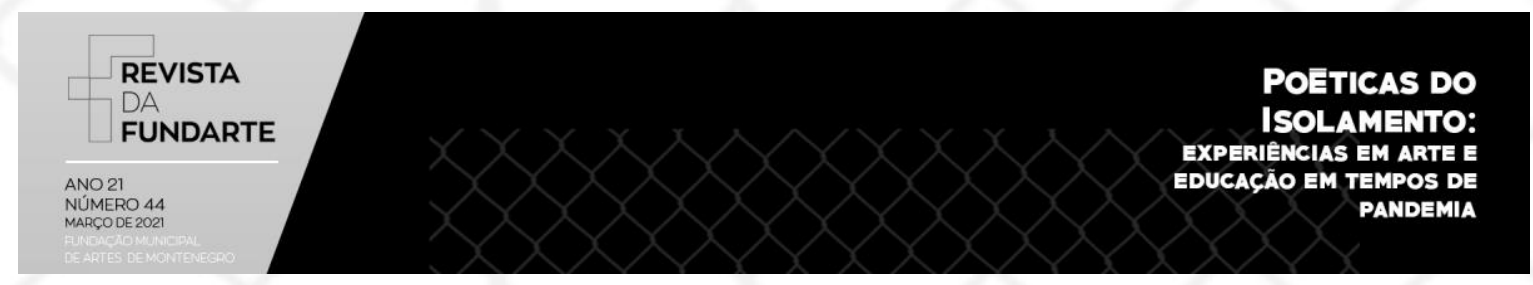

com a obra (no caso o teatro, a encenação teatral), que levaria o ouvinte a redirecionar e refinar seu olhar sobre essa nova relação instaurada, uma "desilusão" cênica que propõe questionamentos.

O outro citado é o teórico francês Antonin $A_{r t a u d}{ }^{7}$, que estabelece sua relação no teatro da crueldade, procurando fazer com que os espectadores saiam desta posição: "em vez de ficarem em face de um espetáculo, são circundados pela performance, arrastados para o círculo da ação que lhes devolve a energia coletiva" (RANCIÈRE, 2012, p. 13). Propondo assim que não haja qualquer distância entre a obra e o ouvinte. Este abdicaria assim de sua posição de observador, tornando-se componente da obra.

Após apresentados tais exemplos, entendo que a ideia de emancipação do espectador está entre a visão questionadora de Brecht, que estabelece uma relação entre espectador e obra, mas que não permite a contaminação de um no outro, ou seja, a relação entre as partes é incompleta. Enquanto o não-distanciamento do ouvinte em Artaud, não possibilita a este a distância necessária para observar e interferir na obra. Metaforizando: enquanto um observa a ilha e não chega nela nunca; o outro está dentro da ilha e não consegue sair dela.

Sendo assim, uma obra que queira ter seus espectadores emancipados precisa motivá-los e tirá-los de seu campo passivo, permitindo sua entrada e contaminação na obra. "A emancipação [...] começa quando se questiona a oposição entre olhar e agir", ou seja, fazer agir, partindo do olhar.

No entanto, "não temos que transformar os espectadores em atores [...] temos que reconhecer [...] a atividade própria ao espectador. Todo espectador é já ator de sua história, todo ator, todo homem de ação, espectador da mesma história" (RANCIÈRE, 2012, p. 21). Não podemos, desse modo, subestimar o potencial do

\footnotetext{
${ }^{7} \mathrm{Na}$ teoria artaudiana a "própria distância reflexiva deve ser abolida. O espectador deve ser retirado da posição de espectador, que examina calmamente o espetáculo que lhe é oferecido. Deve ser desapossado desse controle ilusório, arrastado para o círculo mágico da ação teatral, onde trocará o privilégio de observador racional pelo do ser na posse de suas energias vitais integrais" (RANCIÈRE, 2012, p. 10).
}

ALMEIDA, Railson Gomes. O enxerimento: a prática do Grupo Magiluth e o espectador emancipado de Jacques Rancière. Revista da FUNDARTE. Montenegro, p.01-11, ano 21, oㅡ 44, janeiro/março de 2021.

Disponível em: http://.seer.fundarte.rs.gov.br/index.php/revistadafundarte/index> 30 de março de 2021. 


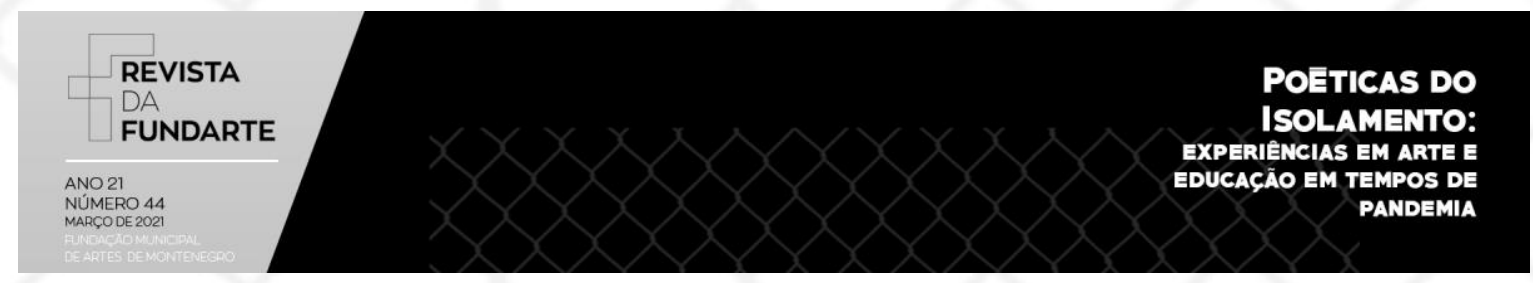

espectador; nem forçá-lo a qualquer ato, propor sem isentar sua liberdade de escolha.

\section{O ENXERIMENTO}

Segundo o Portal online Aulete Digital $^{8}$, o enxerimento pode ser um atrevimento, intrometimento ou indiscrição; agarro-me a esse entendimento para ilustrar minha experiência ao prestigiar "o experimento sensorial em confinamento" (assim o Grupo Magiluth se descreve) Todas as histórias possíveis numa noite qualquer, de uma quinta-feira qualquer, de um dia qualquer, desse confinamento, 0 qual vivencio desde o dia 18 de março de 2020 e que até então não existe previsão de encerramento.

Ver a vida dos outros sem sua autorização é um ato de enxerimento, quando assistimos a uma peça de teatro seja no palco, num ambiente improvisado, ou em meio à cidade, tal enxerimento entre o público e os artistas envolvidos na obra, é um acordo que se estabelece por um determinado momento. O artista, por mais exposto que esteja ainda guarda para si certa privacidade. Não sabemos nada a respeito de sua vida privada, a não ser que ele nos diga onde mora, seu telefone, por onde anda, nada disso não é apresentado previamente. Diferente desse experimento onde somos convidados a seguir os artistas em suas redes sociais e ainda recebemos o contato pessoal deles por meio das ligações. O que antes era privado e particular do artista se torna público para todos aqueles que vivenciam aquela experiência. Tenho até hoje o contato de Giordano Castro que ligou, passei a seguilo nas redes sociais e posso acompanhar sua vida e sua trajetória, por meio da internet.

Pela primeira vez me sinto invadindo a vida alheia dentro do teatro, sendo um enxerido dentro de uma obra de arte. A dramaturgia proposta pelo coletivo se

$8 \mathrm{http}: / /$ www.aulete.com.br/enxerimento

ALMEIDA, Railson Gomes. O enxerimento: a prática do Grupo Magiluth e o espectador emancipado de Jacques Rancière. Revista da FUNDARTE. Montenegro, p.01-11, ano 21, oㅡ 44, janeiro/março de 2021.

Disponível em: http://.seer.fundarte.rs.gov.br/index.php/revistadafundarte/index> 30 de março de 2021. 


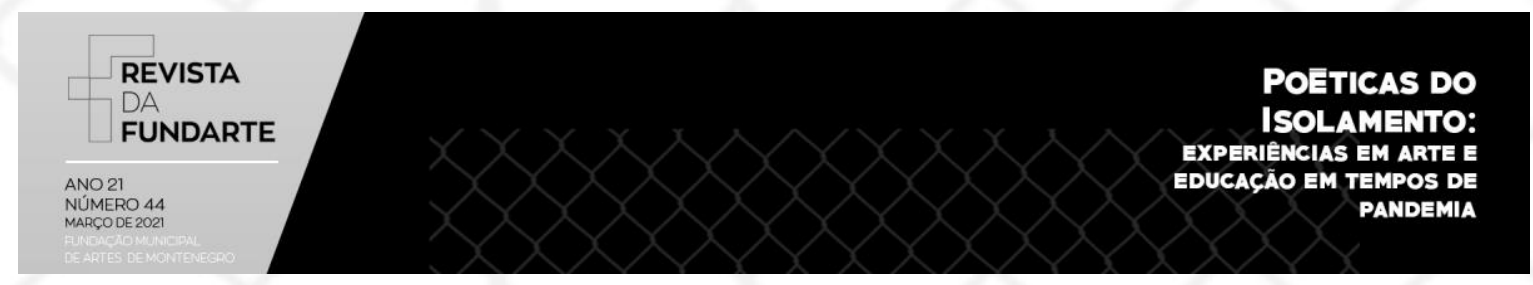

mistura a essa relação pessoal direta, estabelecida por uma ligação no final da noite de uma quinta-feira, quando o ator me liga e procura me transportar para a vida de uma personagem ficcional. É indissociável não pensar que a ficção ganha forma, e aquela ligação não é de um ator, e sim de uma personagem que apresenta a mim pela fala, pelos textos e pelos vídeos que assisto. É muito enxerimento isso tudo.

Talvez seja essa a sensação que Jacques Rancière descreve no conceito de espectador emancipado, quando o sujeito, ao ter contato com a obra de arte se sinta parte dela, emancipando-se do lugar de observador para se tornar um atuante, ou pelo menos parte crucial daquela obra. Quando Giordano me liga, representando o Grupo Magiluth, ele está me convidando para iniciar o teatro. Coube a mim escolher se existiria ou não teatro naquele momento. Foi minha a decisão de atender ele, ouvi-lo. e continuar aquela dramaturgia por leitura, ou busca em sites. Tudo que ocorreu naquela quinta-feira foi um acordo nosso, estabelecido naquele momento, então eu fiz parte dessa obra, do início da ligação com o "boa noite", até o final quando ofereço uma música para a playlist colaborativa.

Assim, entendo o pensamento proposto pelo filósofo francês, que se encaixa perfeitamente dentro do experimento aqui mencionado Todas as histórias possíveis do Grupo Magiluth. O espectador emancipado, nesse texto, é reconfigurado para o espectador enxerido, em alusão a expressão usual no nordeste brasileiro, lugar onde se encontra o coletivo teatral e a mim que fui impactado com esse teatro. Foi uma experiência agradável e teatral que tivera tido há algum tempo, um teatro feito em tempo real e efêmero como ele se apresenta historicamente falando, mas que em decorrência da quarentena mundial vem sofrendo algumas transformações. Muito enxerimento isso tudo.

ALMEIDA, Railson Gomes. O enxerimento: a prática do Grupo Magiluth e o espectador emancipado de Jacques Rancière. Revista da FUNDARTE. Montenegro, p.01-11, ano 21, oㅡ 44, janeiro/março de 2021.

Disponível em: http://.seer.fundarte.rs.gov.br/index.php/revistadafundarte/index> 30 de março de 2021. 


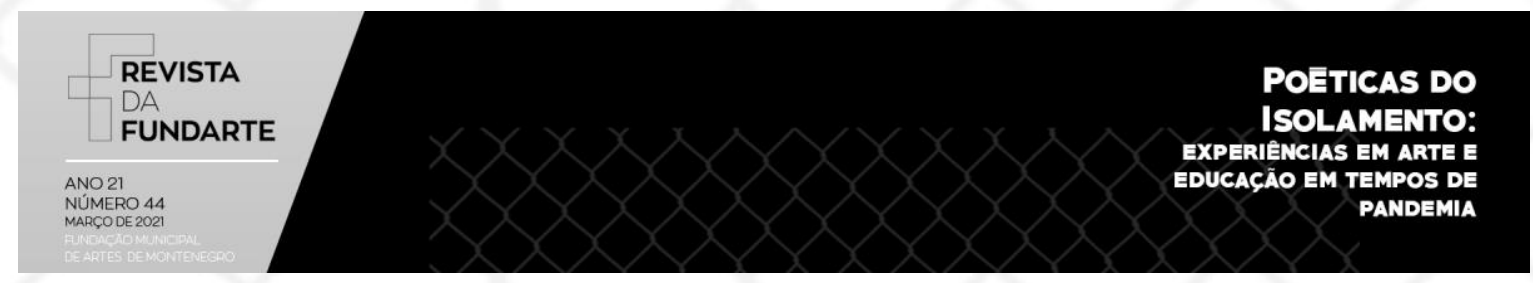

\section{Referências:}

HOULLOU, Jean Raphael Zimmermann; JULIANO, Dilma Beatriz Rocha. O paradoxo do espectador em Rancière . IN: Revista Critica Cultural (Critic), Palhoça SC: UNISUL - Universidade do Sul de SC, 2013, v.8, n.2, p. 417-424.

LEAL, Zulenilton S. Resenha: O espectador emancipado. IN: Revista Temática, João Pessoa - PB: UFPB - Universidade Federal da Paraíba, 2015, Ano XI, n. 11, p. 268 -274 .

MAGILUTH, Grupo. Todas as histórias possíveis - experimento sensorial em confinamento. 2020.

RANCIÈRE, Jacques. O espectador emancipado. Tradução: Ivone C. Benedetti. São Paulo - SP: Editora WMF Martins Fontes, 2012.

ALMEIDA, Railson Gomes. O enxerimento: a prática do Grupo Magiluth e o espectador emancipado de Jacques Rancière. Revista da FUNDARTE. Montenegro, p.01-11, ano 21, oㅡ 44, janeiro/março de 2021.

Disponível em: http://.seer.fundarte.rs.gov.br/index.php/revistadafundarte/index> 30 de março de 2021. 